\title{
SUPERABSORBENTS ENRICHED BY ANORGANIC (NPK) AND ORGANIC (LIGNOHUMATE) NUTRIENTS IN ENVIRONMENTAL SYSTEMS
}

\author{
Petra ZÁVODSKÁ, Martina KLUČÁKOVÁ \\ Brno University of technology, Faculty of Chemistry, Brno, Czech Republic, EU, Petra.Zavodska@vut.cz
}

https://doi.org/10.37904/nanocon.2021.4337

\begin{abstract}
This contribution is focused on superabsorbent materials based on polymerization of partially neutralized acrylic acid. Several types of superabsorbents were prepared. They differed by content of inorganic (NPK fertilizer) and organic (lignohumate) nutrients for their release in soil systems. Superabsorbents were characterized from point of view of their swelling capacity in order to evaluate their ability to control water management soil. Gradual release of incorporated nutrient into water was monitored in time and complemented by measurements of $\mathrm{pH}$ and conductivity, UV-VIS, ICP-OES and lon chromatography. It was found that the nutrients were released from superabsorbents for the duration of several days in the dependence on the type of prepared superabsorbent. In conclusion, simple pot experiments with corn were realized. Corn was grown in presence of each type of superabsorbent and even without it to get differences not only between samples but between samples and corn itself. It was confirmed that the application of superabsorbents can improve soil properties, water management, nutrient uptake, and growth of plants.
\end{abstract}

Keywords: Superabsorbents, NPK, lignohumate, nutrients, soil system

\section{INTRODUCTION}

Superabsorbents (SAPs) are three-dimensionally crosslinked hydrophilic polymers that are capable of swelling and retaining large volumes of water in swollen state [1]. They're not only able to absorb large amount of water but they can do it during short period of time. Also, they can retain absorbed water even under the pressure. Due to this fact they are used widely in traditional water-absorbing materials, such as nappies, hygienic napkins and so on $[2,3]$. For their ability to absorb and contain water and ability to carry nutrients essential for plants, they are used in agriculture as source of water and nutrients. SAPs are used in agriculture not only for this purpose but also for their help to reduce irrigation water consumption, reduce the death rate of plants, improve fertilizer retention in soil, and increase plant growth rate [4]. SAPs find usage in many industries thanks to their ability to absorb water. For example, they are used in diapers or pads. Except for personal care industry they can be find in the construction industry as an addition to concrete in places where is a chance of leaking water, for example they were used construction of English Channel tunnel [5].

Nutrients are essential for plants to be able to grow, develop and produce at their best. Plants need approx. 17 essential nutrients that were grouped into three groups by the amount that plants need. The largest amount of nutrients that plants needs are called primary nutrients or macronutrients. Primary nutrients contain carbon, hydrogen, nitrogen, oxygen, phosphorus, and potassium. Secondary nutrients are needed in moderate amounts compared to primary nutrients and contain calcium, magnesium, and sulphur. Last are micronutrients that are needed in tiny amounts and contain boron, chlorine, copper, iron, manganese, molybdenum, and zinc [6]. As mentioned before plants need nutrients for their growth. Each type of plant has its own optimum nutrient range as well as minimum required level. If the nutrient amount doesn't reach the minimum level plants start to show deficiency symptoms specific to each nutrient. Excessive uptake can also cause improper growth because higher concentration of nutrients can be toxic for the plant [7]. Therefore, motivation for this work was 
to determinate superabsorbents' ability to absorb and hold water and nutrients and to use it in pot experiment that simulated natural conditions in fields. Results from this work could be very helpful to use SAPs in field and especially in the places where it's normally difficult to grow plants.

\section{EXPERIMENTS}

Six different SAPs were prepared (Table 1) using acrylic acid (AA) as monomer for polymerization. Acrylic acid was partially neutralized by adding potassium hydroxide $(\mathrm{KOH})$. Solution of acrylic acid was placed on magnetic stirrer and while stirring constantly potassium hydroxide was added by drops. After partial neutralization cross-linker was added, in this case it was methylene bisacrylamide (MBA). Potassium persulfate (KPS) was added after and was used as an initiating agent. As inorganic nutrients we used NPK and as organic nutrients we used lignohumate (LH) which were added to the mixture and heated up to range of temperatures from 90 to $100^{\circ} \mathrm{C}$ based on the type of SAP. Every type of SAP was labelled by a letter, specifically letters A, B, C, D, H and I and their exact recipe is shown in Table 1. Prepared SAPs were dried in dryer before they were used for swelling capacity measurements.

Table 1 Recipe of used SAPs [8]

\begin{tabular}{|c|c|c|c|c|c|c|}
\hline SAP & A & B & C & D & H & I \\
\hline AA (g) & 14.25 & 14.25 & 14.25 & 14.25 & 14.25 & 14.25 \\
\hline KOH (g) & 4.75 & 4.75 & 4.75 & 4.75 & 4.75 & 4.75 \\
\hline MBA (g) & 0.016 & 0.016 & 0.016 & 0.016 & 0.016 & 0.016 \\
\hline KPS (g) & 0.5 & 0.5 & 0.5 & 0.5 & 0.5 & 0.5 \\
\hline NPK (g) & 0.6602 & 6.602 & 0.6602 & 6.602 & - & - \\
\hline LH (g) & - & - & 1 & 1 & 1 & - \\
\hline
\end{tabular}

Prepared SAPs were characterized by point of view of their swelling capacity. Approximately $50 \mathrm{mg}$ of each SAP was mixed with $100 \mathrm{ml}$ of distilled water and at 24 hours interval for four days was swelling capacity measured by weighing swelled SAPs. SAPs were taken out after the time interval and extracts were used for measuring $\mathrm{pH}$ and conductivity, UV-VIS, ICP-OES and ion chromatography (IC) to monitor release of nutrients from SAPs.

For the study of SAPs influence on plants growth pot experiments with corn were performed. Firstly, corn was sprouted by immersing in the water for 24 hours and put on wet cotton wool then. Sprouted corns were planted to pots with approximately $250 \mathrm{~g}$ of soil and $1 \mathrm{~g}$ of each SAPs. Control samples were also prepared, so corn was planted to pots with only approx. $250 \mathrm{~g}$ of soil. Experiment was performed without water-stress, so every week the plants were watering with approx. $50 \mathrm{ml}$ of water. Three pots were made for each sample and each time interval (46, 60 and 74 days). In one pot were three sprouted corns set. For three time periods it makes 63 pots and 189 sprouted corns total.

\section{RESULTS AND DISCUSSION}

Six types of SAPs were prepared following the recipe shown in Table 1. Each one of them was characterized by swelling capacity that shows that sample $\mathrm{H}$ absorbed the largest amount of water comparing to other types. For example, after 72 hours was swelling coefficient equal to 19.4. On the contrary, the smallest amount of absorbed water is seen in sample $D$, where after 72 hours was swelling coefficient only 5.5. Chyba! Nenalezen zdroj odkazů. shows dependency of swelling capacity on time intervals for each SAPs. It's apparent that sample $H$ (after 72 hours equals to 19.4) and sample $C$ (after 72 hours equals to 15.2) have the largest swelling capacity and sample D (after 72 hours equals 5.5 which was the highest swelling coefficient for sample $D$ ) and sample B (after 72 equals to 7.8 which was again the highest swelling coefficient for sample B) has the 
smallest. According to our results shown in Chyba! Nenalezen zdroj odkazů. it is apparent that presence of lignohumate helps absorbing water whereas presence of higher amount of NPK reduces the possible amount of absorbed water. Results from $\mathrm{pH}$ and conductivity measurement (Table 2) shown that incorporated nutrients in SAPs were released and, in every type of SAP, the longer the time was the more nutrients were released. For example sample D, after 6 hours (0.25 day in Table 2) was $\mathrm{pH}$ equals to 5.37 and after 42 days was equals to 5.5 . Conductivity for sample $D$ after 6 hours was $255.7 \mu S$ and after 42 days was conductivity equal to 275.4 $\mu S$. Contrary to measurement of swelling capacity, NPK helps releasing nutrients. In addition, UV-VIS spectrum was measured for samples $\mathrm{C}, \mathrm{D}$ and $\mathrm{H}$ to monitor release of organic nutrient lignohumate (Chyba! Nenalezen zdroj odkazů.). Results shows that sample $C$ has the highest amount of released lignohumate comparing to other two samples. Specifically, after 42 was $47.67 \mathrm{mg} / \mathrm{g}$ from sample $C$ released while in sample D was released $36.58 \mathrm{mg} / \mathrm{g}$ and in sample $\mathrm{H}$ only $31.42 \mathrm{mg} / \mathrm{g}$. Results from ICP-OES (Table 3) and IC (Table 4) shown that in every measured nutrient were highest amounts measured by sample B and D. In Table 2 and Table 3 it's apparent that sample D released the highest amounts of nutrients. For example, release of potassium. In Table 2 and Table 3 we can see that in sample A released amount of potassium is equal to $30.87 \%$ wt., in sample B $52.29 \%$ wt., in sample C $35.78 \%$ wt., in sample D $56.32 \%$ wt., in sample H $33.94 \%$ wt. and in sample I $28.96 \%$ wt. As mentioned before sample B and D have the highest amounts of released nutrients. But between these two samples, sample $D$ has higher amounts when releasing potassium, phosphorus and $\mathrm{NO}_{3}{ }^{-}$. It's apparent that presence of lignohumate helps release of nutrients.

Also, it's apparent that presence of NPK helps releasing lignohumate as an organic nutrient. At the same time the results shown that higher amount of NPK incorporated (in our work it's $6.602 \mathrm{~g}$ ) slows releasing lignohumate. So, higher amount of NPK incorporated $(6.602 \mathrm{~g})$ has negative influence on swelling capacity and release of lignohumate. The only positive influence was in releasing inorganic nutrients where more elements could and were released. 
Table $2 \mathrm{pH}$ and conductivity measurement

\begin{tabular}{|c|c|c|c|c|c|c|c|c|c|c|c|c|}
\hline \multirow{2}{*}{ Days } & \multicolumn{9}{|c|}{ pH } & \multicolumn{6}{c|}{ Conductivity $(\boldsymbol{\mu S})$} \\
\cline { 2 - 14 } & A & B & C & D & H & I & A & B & C & D & H & I \\
\hline 0.25 & 5.65 & 5.37 & 5.61 & 5.38 & 5.74 & 5.75 & 351.5 & 387.2 & 149.4 & 255.7 & 108.3 & 78.8 \\
\hline 1 & 5.59 & 5.24 & 5.88 & 5.45 & 5.96 & 6.55 & 197.6 & 290.3 & 155.7 & 283.9 & 123.6 & 85.7 \\
\hline 2 & 6.11 & 5.67 & 5.84 & 5.47 & 5.98 & 6.35 & 130.5 & 314.9 & 164.2 & 285.6 & 125.9 & 74.0 \\
\hline 3 & 6.01 & 5.52 & 5.76 & 5.40 & 5.70 & 5.51 & 119.1 & 310.7 & 146.0 & 318.4 & 118.2 & 79.4 \\
\hline 7 & 6.36 & 6.10 & 5.62 & 5.53 & 5.82 & 5.59 & 133.7 & 276.0 & 141.0 & 268.4 & 107.2 & 82.5 \\
\hline 14 & 5.93 & 5.64 & 5.87 & 5.49 & 5.70 & 5.68 & 124.7 & 271.6 & 147.6 & 256.2 & 114.6 & 112.7 \\
\hline 21 & 6.53 & 6.17 & 5.94 & 6.08 & 6.23 & 5.93 & 953 & 281.0 & 154.0 & 302.4 & 107.1 & 83.3 \\
\hline 28 & 6.01 & 5.89 & 6.07 & 5.73 & 6.18 & 5.27 & 114.6 & 282.1 & 141.9 & 267.1 & 103.3 & 85.0 \\
\hline 35 & 6.63 & 6.16 & 6.33 & 6.09 & 6.30 & 6.18 & 103.5 & 287.8 & 139.6 & 285.9 & 113.3 & 95.0 \\
\hline 42 & 6.34 & 5.77 & 6.18 & 5.50 & 5.90 & 5.85 & 75.1 & 270.6 & 124.8 & 275.4 & 130.6 & 34.3 \\
\hline
\end{tabular}

Table 3 ICP-OES measurement of potassium and phosphorus

\begin{tabular}{|c|c|c|c|c|c|c|c|c|c|c|}
\hline \multirow{2}{*}{ Days } & \multicolumn{9}{|c|}{ Potassium [\% wt.] } & \multicolumn{4}{c|}{ Phosphorus [\% wt.] } \\
\cline { 2 - 12 } & A & B & C & D & H & I & A & B & C & D \\
\hline 0.25 & 37.63 & 59.66 & 42.03 & 54.18 & 30.98 & 21.93 & 24.55 & 84.58 & 16.20 & 94.37 \\
\hline 1 & 32.63 & 63.22 & 46.52 & 59.83 & 34.62 & 23.74 & 26.52 & 95.76 & 57.68 & 89.78 \\
\hline 2 & 36.57 & 62.75 & 48.03 & 57.63 & 34.72 & 27.07 & 34.79 & 86.70 & 59.91 & 99.66 \\
\hline 3 & 34.96 & 57.16 & 42.76 & 66.48 & 34.29 & 23.95 & 33.10 & 88.31 & 61.52 & 93.14 \\
\hline 7 & 43.50 & 62.60 & 43.81 & 56.48 & 31.22 & 24.03 & 36.06 & 89.45 & 71.87 & 95.71 \\
\hline 14 & 33.22 & 55.19 & 44.56 & 54.45 & 32.69 & 33.39 & 39.64 & 85.92 & 91.77 & 95.76 \\
\hline 21 & 29.53 & 59.45 & 44.66 & 62.23 & 31.35 & 34.17 & 33.13 & 89.76 & 100.00 & 100.00 \\
\hline 28 & 34.88 & 58.35 & 43.16 & 54.37 & 30.23 & 23.61 & 37.17 & 100.00 & 100.00 & 100.00 \\
\hline 35 & 29.99 & 59.22 & 44.19 & 57.45 & 30.43 & 26.56 & 22.58 & 100.00 & 100.00 & 100.00 \\
\hline 42 & 30.87 & 52.29 & 35.78 & 56.32 & 33.94 & 28.96 & 33.00 & 100.00 & 100.00 & 100.00 \\
\hline
\end{tabular}

Table 4 IC measurement of $\mathrm{NO}_{3}{ }^{-}$and $\mathrm{PO}_{4}{ }^{3-}$

\begin{tabular}{|c|c|c|c|c|c|c|c|c|}
\hline \multirow{2}{*}{ Days } & \multicolumn{4}{|c|}{ NO3- [\% wt.] } & \multicolumn{4}{c|}{ PO43- [\% wt.] } \\
\cline { 2 - 9 } & A & B & C & D & A & B & C & D \\
\hline 0.25 & 47.51 & 57.61 & 38.95 & 75.80 & 26.00 & 60.03 & 43.58 & 66.45 \\
\hline 1 & 28.99 & 89.36 & 46.76 & 97.16 & 48.82 & 80.82 & 72.00 & 84.77 \\
\hline 2 & 78.53 & 82.11 & 81.09 & 100.00 & 58.35 & 88.53 & 89.82 & 93.11 \\
\hline 3 & 63.68 & 90.65 & 81.01 & 95.03 & 81.10 & 99.13 & 100.00 & 83.93 \\
\hline 7 & 65.26 & 82.43 & 86.63 & 94.28 & 89.72 & 100.00 & 83.56 & 99.17 \\
\hline 14 & 72.93 & 98.10 & 66.80 & 95.81 & 72.32 & 100.00 & 59.93 & 99.10 \\
\hline 21 & 78.96 & 89.68 & 79.15 & 98.85 & 66.61 & 98.55 & 57.29 & 91.16 \\
\hline 28 & 56.88 & 100.00 & 77.00 & 100.00 & 73.20 & 100.00 & 50.46 & 96.56 \\
\hline 35 & 66.67 & 100.00 & 85.57 & 100.00 & 74.58 & 100.00 & 37.77 & 100.00 \\
\hline 42 & 78.92 & 94.76 & 74.13 & 100.00 & 68.73 & 100.00 & 62.55 & 97.79 \\
\hline
\end{tabular}


As we can see in Table 3 and Table 4 some results are showing $100 \%$ wt. of released nutrients. These results were our intentions because SAPs were used only as a carrier of nutrients. Therefore, we used them in pot experiment because results showed no interaction between SAPs and nutrients.

Pot experiments were realized in controlled environment with UV lamp simulated day and night. After each cultivation corn plants were weighed, roots were measured and scanned. Scans were analysed in program Harmonic and Fractal analyser (HARFA) to characterize branching of root systems. Result showed positive correlation between roots length and weigh of the plant which means the heavier the plants were the longer the roots were. In addition, the heavier plants had more complex root systems than the lighter ones. Scans of roots showed only a small difference after the first cultivation time (46 days) therefore there is apparent that almost all plants had their optimal

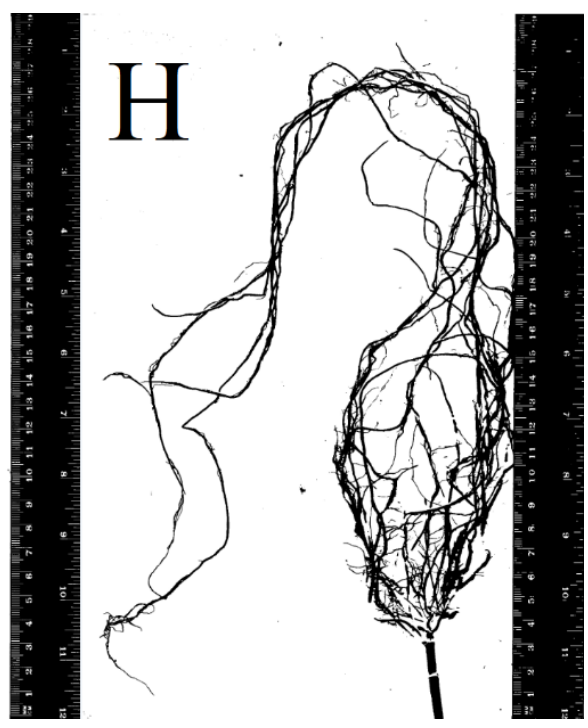

Figure 3 Scans of roots $\mathrm{A}$ and $\mathrm{H}$ after 74 days range of nutrients and water. After second cultivation (60 days) there were difference in roots and even in plants' weigh. The largest roots were measured by plants with sample A and B. And after the last cultivation time (74 days, results shown in Figure 4) some plants died already, for example by sample B all plants died, but plants by samples with lignohumate were still viable and in good condition. Figure 3 shows root of sample $\mathrm{A}$ and $\mathrm{H}$ after 74 days (last cultivation time). After the pot experiment it was apparent that presence of lignohumate and the right amount of NPK $(0.6602 \mathrm{~g}$ in our work) incorporated in superabsorbents has positive influence on plant growth.

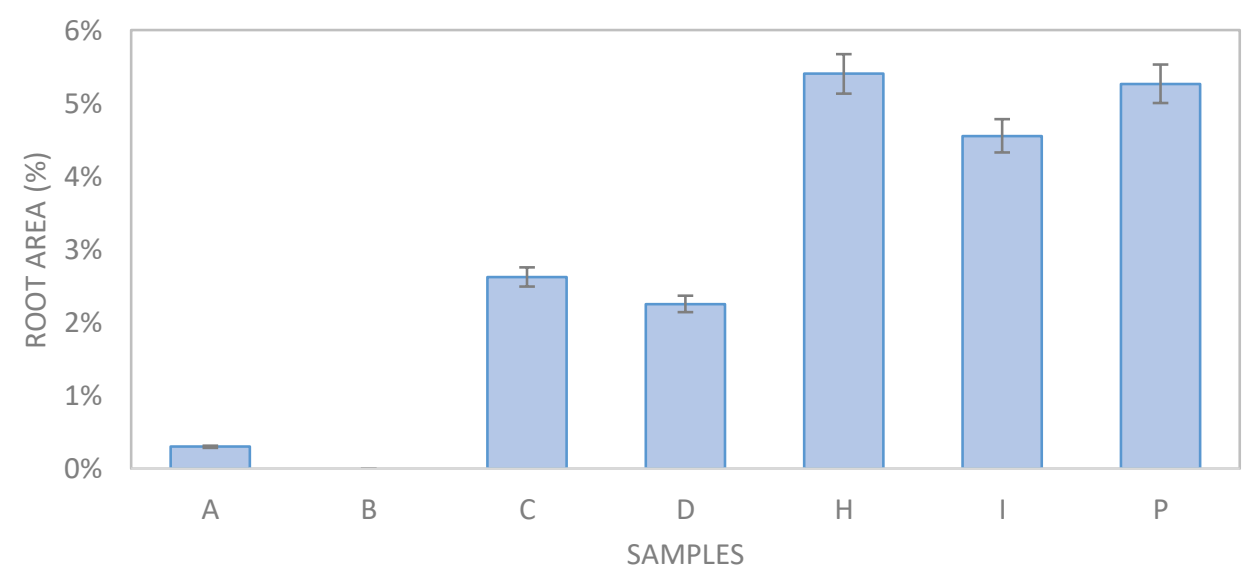

Figure 4 Results from HARFA after last cultivation (74 days)

\section{CONCLUSION}

Superabsorbents were prepared, characterized, and used in pot experiment. Measurement of swelling capacity showed the highest amount of absorbed water by sample $\mathrm{H}$ after 72 hours that equals to 19.4 and the lowest by sample $D$ after 72 hours that equals to 5.5 . Both samples contain lignohumate and sample $D$ has higher amount of NPK (6.602 g) on top of it. It's apparent that higher amount of NPK reduce the possible 
amount of absorbed water. On the contrary presence of lignohumate increase the possible amount of absorbed water. Conductivity and $\mathrm{pH}$ measurements confirmed releasing of nutrients into distilled water withing samples. As mentioned before $\mathrm{pH}$ of sample $\mathrm{D}$ after 6 hours was equal to 5.38 and after 42 days was equal to 5.5 . ICP-OES and IC also confirmed releasing of nutrients. In Table 2 and Table $\mathbf{3}$ is shown that in sample A released amount of potassium is equal to $30.87 \%$ wt., in sample B $52.29 \%$ wt., in sample C $35.78 \%$ wt., in sample D $56.32 \%$ wt., in sample H $33.94 \%$ wt. and in sample I $28.96 \%$ wt. Therefore, it's apparent that lignohumate incorporated in superabsorbent helps releasing of nutrients. As well as inorganic nutrients the lignohumate can be released. The highest amount of released lignohumate was by sample $C$, that has lower amount of NPK than sample D. Specifically, after 42 was $47.67 \mathrm{mg} / \mathrm{g}$ from sample C released while in sample D was released $36.58 \mathrm{mg} / \mathrm{g}$ and in sample $\mathrm{H}$ only $31.42 \mathrm{mg} / \mathrm{g}$. As mentioned before the higher amount of NPK incorporated $(6.602 \mathrm{~g})$ in SAPs has negative influence on swelling capacity and release of lignohumate.

Pot experiment was made to use prepared SAPs in real condition. Corns were growth with and without presence of SAPs in soil and measured after cultivation time. After the first cultivation time there were barely any differences between plants with each SAP and even the soil itself. After the second cultivation time plants in soil without SAPs started to die while plants growth in presence of SAPs were still viable and in good condition. After the last cultivation time plants started to die and wither even in presence of SAPs. But still there were plants that stayed viable and in good condition.

Usage of SAPs has its advantages but also some disadvantages, for example they remain in soil even after end of cultivation. Even so, the advantages outweigh the disadvantages and usage of SAPs has a bright future in agriculture, because they are able to absorb and contain water and ability to carry nutrients essential for plants. Also, they can reduce irrigation water consumption, reduce the death rate of plants, improve fertilizer retention in soil, and increase plant growth rate.

\section{REFERENCES}

[1] BEHERA, Sabyasachi and Prakash A. MAHANWAR. Superabsorbent polymers in agriculture and other applications: a review. Polymer-Plastics Technology and Materials. 2020, vol. 59, no. 4, pp. 341-356.

[2] DADHANIYA, P., PATEL, M. \& PATEL, R. Swelling and dye adsorption study of novel superswelling [Acrylamide/N-vinylpyrrolidone/3(2-hydroxyethyl carbamoyl) acrylic acid] hydrogels. Polym. Bull. 2006, vol. 57, pp. 21-31. Available from: https://doi.org/10.1007/s00289-006-0531-5

[3] LIANG, Rui, Mingzhu LIU and Lan WU. Controlled release NPK compound fertilizer with the function of water retention. Reactive and Functional Polymers. 2007, vol. 67, no. 9, pp. 769-779.

[4] MOHANA RAJU, $K$ and M PADMANABHA RAJU. Synthesis of novel superabsorbing copolymers for agricultural and horticultural applications. Polymer International. 2001, vol. 50, no. 8, pp. 946-951.

[5] BUCHHOLZ, Fredric L. Superabsorbent Polymers: An Idea Whose Time Has Come. Journal of Chemical Education. 1996, vol. 73, no. 6, pp. 512-515.

[6] RILEY, LEE E.; DUMROESE, R. KASTEN; LANDIS, THOMAS D. National Proceedings: Forest and Conservation Nursery Associations-2003. Proc. RMRS-P-33. Fort Collins, CO: U.S. Department of Agriculture, Forest Service, Rocky Mountain Research Station. 2004, p. 156.

[7] SILVA, J. A., UCHIDA, R. S. (ed.). Plant Nutrient Management in Hawaii's Soils. 1st ed. Honolulu: University of Hawaii at Manoa, 2000. ISBN 1-929235-08-8.

[8] KRATOCHVILOVA, Romana, SEDLACEK, Petr, PORIZKA, Jaromir and KLUCAKOVA, Martina. 2021. Composite materials for controlled release of mineral nutrients and humic substances for agricultural application. Soil Use and Management. 2021, vol. 37, no. 3, pp. 460-467. 